\title{
MEIOS E CRITÉRIOS DE INDEXAÇÃO: EM BUSCA DA GLOBALIZAÇÃO DE SEU PERIÓDICO CIENTÍFICO - A EXPERIÊNCIA DA REVISTA DE EPIDEMIOLOGIA E CONTROLE DE INFECÇÃO
}

\author{
Júlia Kern ${ }^{1}$ \\ Andreia Rosane de Moura Valim ${ }^{2}$ \\ Marcelo Carneiro ${ }^{3}$ \\ Lia Gonçalves Possuelo ${ }^{4}$
}

Ao longo dos últimos anos, as publicações científicas de pesquisadores brasileiros vêm aumentando, devido principalmente à introdução das tecnologias de informações, como computadores, redes de comunicação e à maior popularização dos periódicos científicos online, conhecidos também como revistas científicas, que tem se revelado uma fonte inesgotável e segura para o compartilhamento do conhecimento e da produção científica (VOLPATO, 2003; FREIRE, 2009; GARRIDO, 2010).

O Sistema Eletrônico de Editoração de Revistas (SEER) faz parte da nova geração de sistemas de gerenciamento de periódicos científicos e, no Brasil, ele surge como modelo alternativo de publicação do conhecimento científico para ampliar o acesso, a preservação e o impacto das pesquisas e dos resultados daí provenientes (ARELLANO, 2005). É importante saber que para que os periódicos científicos sejam difundidos e tenham alcance mundial, se torna fundamental o processo de indexação e inclusão destes em portais de periódicos, bases de dados e repositórios digitais (SANTOS, 2011).

Os portais de periódicos, nada mais são, que sites na internet que exercem a função de agregador e de índice, tendo por objetivo ajudar os pesquisadores a encontrarem informações específicas acerca de autores, títulos, temas, etc. Um portal de periódicos tem a funcionalidade de agregar informações, aplicações e serviços relevantes aos usuários, filtrando a variedade de informação por meio de uma interface única, como exemplo podemos citar o Portal de Periódicos da CAPES (GARRIDO, 2010).

\footnotetext{
${ }^{1}$ Curso de Farmácia da Universidade de Santa Cruz do Sul - UNISC e Secretária da Revista de Epidemiologia e Controle de Infecção. <julia.kern@ hotmail.com>

${ }^{2}$ Programa de Pós Graduação em Promoção da Saúde da Universidade de Santa Cruz do Sul - UNISC, Editora da Revista de Epidemiologia e Controle de Infecção. <avalim@unisc.br>

${ }^{3}$ Comissão de Controle de Infecção Hospitalar do Hospital Santa Cruz, Editor da Revista de Epidemiologia e Controle de Infecção. <carneiromarcelo@yahoo.com.br>

${ }^{4}$ Programa de Pós Graduação em Promoção da Saúde na Universidade de Santa Cruz do Sul - UNISC, Editora da Revista de Epidemiologia e Controle de Infecção. 〈liapossuelo@unisc.br>
} 
De acordo com SANTOS (2011), os portais não têm tanto impacto quanto os diretórios e as bases de dados. Os diretórios são sites que irão fornecer as características e informações do periódico, como o título, editores, área de conhecimento, o ISSN, o link para acesso e entre outras questões. Os diretórios também podem ser conhecidos como repositórios, onde os artigos são "depositados" de maneira organizada, podendo ser institucional, quando lidam com a produção científica de uma determinada instituição, ou temáticos, quando possuem produção cientifica em uma determinada área, podemos citar como exemplo o Scielo, que é um diretório institucional (PACKER, 2011).

Base de dados, especificamente, é a seleção de parte ou do total de outra coleção de dados, constituída, no mínimo, por um arquivo e concebida para determinado fim ou para um dado sistema de processamento de dados (SANTOS, 2011). Segundo Faria e Pericão (2008), as bases de dados podem conter apenas referências e, nesse caso, designam-se "referenciais"; ou conter dados ou textos completos e, então, se designam "fonte".

O aumento na produção das publicações periódicas no formato eletrônico requer dos editores científicos o estabelecimento de critérios rigorosos, para que as suas publicações apresentem conteúdo significativo e estrutura editorial e técnica nos padrões estabelecidos pelas normas de editoração científica eletrônica, o que favorece a indexação dessas publicações em bases de dados conceituadas (SANTOS, 2011).

DANTAS (2004) deixa muito claro que editores, avaliadores, pesquisadores e autores possuem papel fundamental para que os critérios importantes para indexação das revistas científicas sejam seguidos. Entre os critérios mais exigidos, podemos citar: manutenção da periodicidade e regularidade de publicação da revista; submissão de artigos enviados para análise para revisão aos pares (peer review); publicação de artigos originais com boa metodologia científica e estatística; presença de uma ficha catalográfica e expediente da revista; caráter de internacionalidade à revista (publicação de artigos científicos em outras línguas, como inglês e espanhol, e citação de artigos de autores de outros países); normas para autores e padronização da formatação dos artigos, seguindo corretamente as normas a qual a revista indica (SANTOS 2011, DANTAS 2004).

No que se refere à atuação como bolsista na Revista de Epidemiologia e Controle de Infecção (RECI), destaca-se que esta, atualmente, está no quarto ano de publicação, utilizando todos os recursos da plataforma SEER para a editoração de manuscritos. É uma publicação oficial do Núcleo Hospitalar de Epidemiologia do Hospital Santa Cruz e do Programa de Pós Graduação em Promoção da Saúde da Universidade de Santa Cruz do Sul (Unisc), Santa Cruz do Sul, Rio Grande do Sul, Brasil. O corpo editorial é composto por profissionais de diversas 
instituições de ensino e com uma alta capacidade crítica e formadora de opinião. Este periódico é um dos "veículos" para a divulgação de estudos científicos relacionados aos assuntos de vigilância epidemiológica, bem como aos de controle de infecção relacionados às doenças de notificação compulsória, doenças infecciosas, saúde ocupacional e áreas correlatas. A periodicidade é trimestral, com artigos originais de pesquisa clínica e experimental, artigos de revisão sistemática de literatura, metanálises, artigos de opinião, comunicações, imagens e cartas ao editor. Em situações oportunas são elaborados suplementos com assuntos específicos como consensos, anais de eventos e séries especiais.

Até o momento a RECI está indexada nas seguintes bases: DOAJ, Latindex, $e$ revistas, Eletronic JornalsLlibrary e Sumários.org, todas internacionais, exceto a última. Recentemente foram encaminhados os formulários para solicitação de indexação no LILACS e REDALYC, os quais retornaram a avaliação contendo uma série de recomendações que devem ser acatadas para que o periódico seja indexado nestas bases internacionais de alto impacto. As alterações recomendadas estão sendo realizadas e em breve estaremos reencaminhando os formulários com nova solicitação de indexação nestas bases de dados.

Considera-se de extrema importância que todas as revistas, principalmente as iniciantes, sigam os critérios para se autoqualificar e, portanto, pertencer aos índices de referência, isto é, estar indexado, para que estes periódicos e a pesquisa que comunicam, integrem de modo sistemático a memória e os fluxos de informação científica e sejam, portanto, habilitados a participar dos processos de recuperação e avaliação de informação científica (PACKER, 2011).

\section{REFERÊNCIAS}

ARELLANO, M. Á. M.; SANTOS, R. dos; FONSECA, R. da. SEER: DISSEMINAÇÃO DE UM SISTEMA ELETRÔNICO PARA EDITORAÇÃO DE REVISTAS CIENTÍFICAS NO BRASIL. Arquivística.net, Rio de Janeiro, v. 1, n. 2, p. 75-82, 2005.

DANTAS, P. E. C. Indexação bibliográfica em bases de dados: O que é? Para que serve? Onde estamos? Arq Bras Oftalmol., v. 67, n. 4, p 569-70, 2004.

FARIA, M. I.; PERICÃO, M. da G. Dicionário do livro. Coimbra: Almedina, 2008.

FREIRE, G. H. de A.; FREIRE, I. M. Vida longa (à) revisão pelos pares. Inf. \& Soc.: Est., João Pessoa, v. 19, n. 3, p. 9, 2009.

GARRIDO, I. dos S.; RODRIGUES, R. S. Portais de periódicos científicos online: organização institucional das publicações. Perspect. ciênc. inf., Belo Horizonte, v. 15, n. $2,2010$. 
PACKER, A. L. Os periódicos brasileiros e a comunicação da pesquisa nacional. Revista USP, São Paulo, n. 89, p. 26-61, 2011.

SANTOS, G. C. Fontes de indexação para periódicos científicos: um guia para bibliotecários e editores. Campinas: E-Color, 2011.

VOlPATO, G. L.; FREITAS, E. G. de. Desafios na publicação científica. Pesqui Odontol Bras, v. 17, supl. 1, p. 49-56, 2003. 